\title{
Granulocyte and Granulocyte-Macrophage Colony-Stimulating Factors in Cord and Maternal Serum at Delivery
}

\author{
K. E. M. BAILIE, A. E. IRVINE. J. M. BRIDGES. AND B. G. MCCLURE \\ Departments of Haematolog! /K.E.M.B., A.E.I., J.H.B./ and Child Health /B.G.11.J. The Que'en S L'niversity of \\ Belfast, Royal I'ictoria Hospital. Belfast. BT12 6 B.4. Northern Ireland
}

\begin{abstract}
Impaired neutrophil responses contribute to the neonate's increased susceptibility to infection. Because granulocyte colony-stimulating factor (G-CSF) and granulocyte-macrophage colony-stimulating factor (GM-CSF) enhance granulocyte and macrophage number and function, their use in the management of neonatal sepsis may be beneficial. Little is known about the endogenous levels of G-CSF and GM-CSF. In adults, raised values for G-CSF, but not GM-CSF, have been demonstrated in patients with infection, and conflicting data has emerged regarding CSF levels in neonates. We have used an ELISA to measure maternal and cord serum G-CSF and GM-CSF at the time of delivery, with gestational age between 25 and 42 wk. In mothers, an inverse linear relationship between gestational age and GM-CSF levels $(p=0.049)$ was found, but no association with G-CSF levels was observed. In neonates, a quadratic association was found between GM-CSF levels and gestational age $(p=0.019)$, whereas G-CSF levels showed an inverse linear association $(p=0.015)$. In addition, an association was found between maternal and cord GM-CSF ( $p=0.007)$ but not G-CSF levels in paired samples. The effect of gestational age on the cytokine levels could not be explained by the white cell count, the absolute neutrophil count, pregnancy-induced hypertension, or the presence of infection. We suggest that I) GMCSF levels in mothers vary throughout gestation and may have a role in the maintenance of normal pregnancy; 2) GCSF and GM-CSF levels in neonates vary with gestational age and may have a developmental role; and 3) G-CSF has theoretical benefit in the management of neonatal neutropenia and sepsis; clinical trials are now needed to establish its optimal use. (Pediatr Res 35: 164-168, 1994)
\end{abstract}

\section{Abbreviations}

CSF, colony-stimulating factor

G-CSF, granulocyte colony-stimulating factor

GM-CSF, granulocyte-macrophage colony-stimulating factor

PIH, pregnancy-induced hypertension

WCC, white cell count

ANC, absolute neutrophil count

Received July 14. 1992; accepted February 9. 1993

Correspondence and reprint requests: Dr. K. E. M. Bailie, Department of Haematology, Royal Victoria Hospital, Grosvenor Road, Belfast BT12 6BA. Northern Ireland.

Supported by a Royal Victoria Hospital Research Fellowship Award and by The Northern Ireland Mother and Baby Appeal.
Neonatal sepsis remains an important clinical problem contributing to significant morbidity and mortality (1-5). The neonate is at increased risk of sepsis as a result of a number of immunologic defects (6), including impaired neutrophil function (7). The ability to enhance the neutrophil's response to infection would thus be an attractive adjunct to the conventional management of neonatal sepsis.

The hemopoietic growth factors G-CSF and GM-CSF, in addition to their role in the development of granulocyte and macrophage lineages, are capable of affecting mature cell function $(8,9)$. These effects include the "priming" of the neutrophil's response to inducers of the respiratory burst mechanism $(10,11)$, influencing chemotaxis $(12-14)$ and phagocytosis $(15,16)$, and altering surface membrane receptor expression (17-20).

The clinical use of G-CSF and GM-CSF has included the acceleration of neutrophil recovery after chemotherapy and bone marrow transplantation, the treatment of neutropenia associated with infections, myelodysplasia or irradiation exposure, and congenital neutropenia $(21-26)$. Their use in the management of infection has not been evaluated. Animal studies have suggested that an improved outcome in neonatal sepsis may be achieved using a combination of G-CSF or GM-CSF with antibiotics (2729). Roberts et al. (30) have reported the use of G-CSF in an infected human neonate with neutropenia without adverse effect. resulting in an improvement in neutrophil count and elimination of sepsis.

Despite this increasing clinical use, little is known about the endogenous levels and significance of circulating G-CSF and GM-CSF. Serum GM-CSF levels are undetectable in normal healthy adults $(9,31)$, and raised levels have not been documented yet. In contrast, raised serum G-CSF levels have been found in $10 \%$ of normal adults (32), in the presence of infection (33, 34), and some cases of congenital neutropenia (35). In fullterm healthy neonates, Laver et al. (36) measured G-CSF and GM-CSF using a bioassay and demonstrated raised levels of both cytokines when compared with normal adults. However, Cairo et al. $(37,38)$ were unable to detect G-CSF or GM-CSF in a similar group using an immunoassay. Data concerning serum G-CSF and GM-CSF levels in premature neonates have not been reported.

The aim of this study was to examine the endogenous levels of G-CSF and GM-CSF in cord blood at various stages of gestation and to examine the influence of maternal CSF levels, infection, and the reasons for premature delivery on the values obtained.

Ethical approval for the study was obtained from The Research Ethical Committee of the Faculty of Medicine of The Queen's University of Belfast.

\section{MATERIALS AND METHODS}

Subjects. Mothers and babies were chosen at random from patients attending the Royal Maternity Hospital, Belfast. The 
neonates were all singletons and ranged in gestational age from 25 to $42 \mathrm{wk}$ at the time of delivery. Premature delivery was precipitated by the following maternal antenatal complications: $\mathrm{PIH}$, diabetes mellitus, bleeding, or premature rupture of membranes (at $<36$ completed wk), or fetal distress. Thirty-three neonates were delivered vaginally, and 48 were delivered by cesarean section, of which 36 were elective procedures.

The incidence of infection in both mothers and babies was obtained from case note review. Maternal infection was diagnosed when pyrexia of $38^{\circ} \mathrm{C}$ or more occurred or when cultures of urine, sputum, or vaginal swab were found to be positive. Only episodes occurring $48 \mathrm{~h}$ before or $48 \mathrm{~h}$ after delivery were considered to have a potential influence on cytokine levels at the time of delivery. Neonatal infection was diagnosed by clinical assessment, with or without positive cultures of blood, urine, gastric aspirate, or bronchial secretions. Only early infection (39), occurring within the first $48 \mathrm{~h}$ of delivery, was considered to have a potential influence on cytokine levels at birth. The perinatal details of the study cases are summarized in Table 1.

Serum samples. After patients provided informed consent, blood samples were obtained from the mother and the umbilical cord at the time of delivery. The clotted samples were immediately separated, and the sera were stored in aliquots at $-20^{\circ} \mathrm{C}$ until analysis. This form of storage has previously been shown not to alter immunoassay results (40). At the same venipuncture, a sample was drawn to record the WCC and differential WCC.

ELISA. Commercially available assay kits for the measurement of G-CSF (Amgen Biologicals, Thousand Oaks, CA, sensitivity $5 \mathrm{ng} / \mathrm{L}$ ) and GM-CSF (Medical Resources Ltd., Sydney, Australia, sensitivity $0.5 \mathrm{ng} / \mathrm{L}$ ) were used. Both assays are based on the double-antibody sandwich method. Antibody precoated plates were incubated with standards or serum samples in duplicate. Rabbit anti-CSF, horseradish peroxidase-conjugated antirabbit antibody, and horseradish peroxidase substrate were added sequentially, with a washing step before each addition to remove uncaptured components. The final horseradish peroxidase substrate reaction was terminated by the addition of a weak acid solution before reading the absorbance on an ELISA plate reader (Dynatech MR 700, Dynatech, Cambridge, MA). No crossreactivity with other cytokines or other serum components has been reported (manufacturer's data). A standard curve constructed with the means of the duplicate results was used to determine the values for CSF in the test sera.

Statistical analysis. Mother-baby pairs were divided into five groups by gestational age. Because of the occurrence of values below the sensitivity of the assays, mean and SD could not be calculated for each group. Hence the actual values obtained in the ELISA were catagorized into "raised" and "not raised"

Table 1. Summary of perinatal characteristics

\begin{tabular}{lccccc}
\hline & \multicolumn{5}{c}{ Group } \\
\cline { 2 - 5 } & 1 & 2 & 3 & 4 & 5 \\
\hline Gestation (wk) & $24-28$ & $28-32$ & $32-36$ & $36-40$ & $40-44$ \\
Total number of & 9 & 17 & 23 & 28 & 5 \\
$\quad$ mother-baby pairs & & & & & \\
Delivery & & & & & \\
$\quad$ Normal & 3 & 6 & 13 & 8 & 3 \\
$\quad$ Cesarean section & 6 & 11 & 10 & 19 & 2 \\
Elective & 2 & 7 & 8 & 17 & 0 \\
Perinatal complications & & & & & \\
$\quad$ PIH & 4 & 8 & 7 & 2 & 0 \\
$\quad$ Diabetes & 0 & 1 & 2 & 0 & 0 \\
Premature R.O.M.* & 5 & 5 & 10 & 0 & 0 \\
$\quad$ Prolonged R.O.M. & 0 & 0 & 2 & 0 & 0 \\
$\quad$ Maternal infection & 2 & 4 & 4 & 3 & 1 \\
$\quad$ Neonatal infection & 2 & 2 & 1 & 0 & 0 \\
\hline
\end{tabular}

* R.O.M., rupture of membranes. groups, with reference to the expected normal adult value. The normal adult values were less than $30 \mathrm{ng} / \mathrm{L}$ for GM-CSF (9) and less than $50 \mathrm{ng} / \mathrm{L}$ for G-CSF (8). The values for WCC and ANC were transformed using natural logarithms before analysis. The continuous variables, namely, gestation, WCC, and ANC, were evaluated for association with CSF levels using independent samples $t$ tests. The analysis of WCC and ANC were then adjusted for the confounding effects of gestation using logistic regression analysis. The variables $\mathrm{PIH}$ and infection were classified as either present or absent and were initially evaluated for association with CSF levels using the $\chi^{2}$ test. These associations were then reexamined in five strata defined by gestational age. using the Mantel-Haenstal stratified $\chi^{2}$ test to adjust for the confounding effects of gestation.

\section{RESULTS}

The ranges of results obtained by ELISA for each gestational age group are shown in Figures 1 through 4. Cases in which the levels of cytokine were below the sensitivity of the assay were, for illustrative purposes only, assigned a value of $5 \mathrm{ng} / \mathrm{L}$ (GMCSF) and $20 \mathrm{ng} / \mathrm{L}$ (G-CSF). Tables 2 and 3 give a summary of the statistical analysis.

GM-CSF values were obtained in 56 maternal sera, of which $18 \mathrm{had}$ raised values ranging from 48 to $190 \mathrm{ng} / \mathrm{L}$ (Fig. 1). An inverse linear association between GM-CSF level and stage of gestation was found ( $p=0.049)$.

GM-CSF values were obtained in 58 cord sera, of which 14 had raised values ranging from 32 to $200 \mathrm{ng} / \mathrm{L}$ (Fig. 2). A quadratic association between gestational age and cord GM-CSF level was demonstrated $(p=0.019)$, with the greatest frequency of raised values occurring between 28 and $36 \mathrm{wk}$. In addition. an association between GM-CSF levels in maternal and cord sera was noted $(p=0.007)$.

G-CSF values were obtained in 46 maternal sera, of which six were found to have raised levels ranging from 250 to $1000 \mathrm{ng} / \mathrm{L}$ (Fig. 3). These levels occurred between 28 and $36 \mathrm{wk}$, but no association with gestational age could be demonstrated.

G-CSF values were obtained in 64 cord sera, of which 15 were found to have raised values ranging from 75 to $3750 \mathrm{ng} / \mathrm{L}$ (Fig. 4). An inverse linear association between G-CSF level and gestational age was shown $(p=0.015)$. No correlation was seen between maternal and cord G-CSF levels.

G-CSF or GM-CSF levels in cord or maternal sera were not

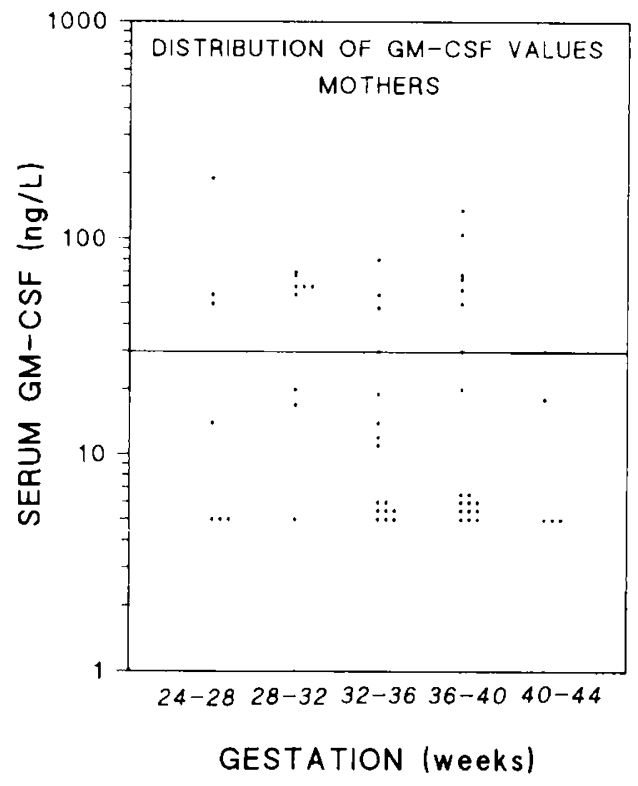

Fig. 1. Distribution of maternal serum GM-CSF values at delivery between 24 - and 42 -wk gestation. 


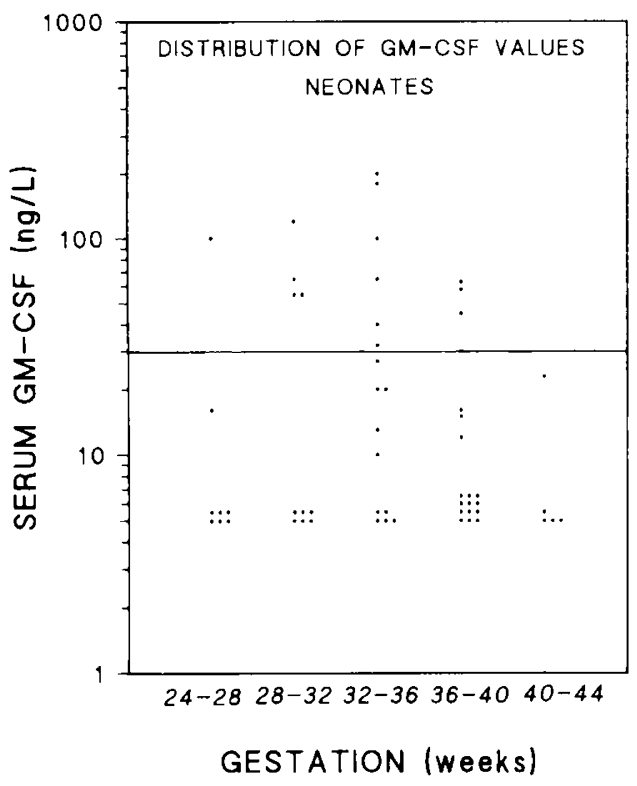

Fig. 2. Distribution of cord serum GM-CSF values at delivery between 24- and 42-wk gestation.

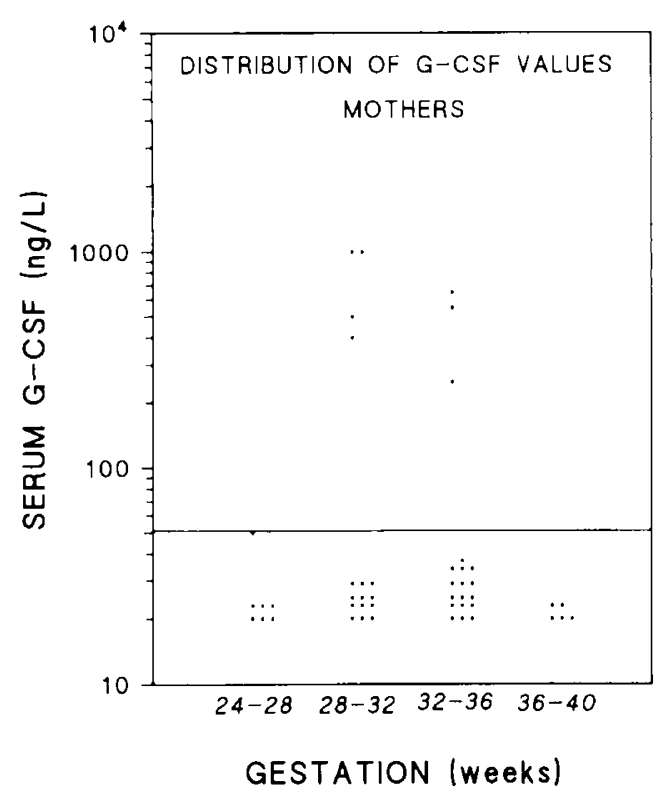

Fig. 3. Distribution of maternal serum G-CSF values at delivery between 24 - and 42-wk gestation.

associated with the WCC or ANC or with the presence of infection or PIH. In addition, the observed effect of gestation could not be accounted for by any of these variables (Tables 2 and 3).

\section{DISCUSSION}

The role of G-CSF and GM-CSF in the control of hematopoiesis and their effects on mature cell function have been well established (21-26). Measurement of circulating CSF in adults has indicated that under normal conditions both G-CSF and GM-CSF are either undetectable or present in very small amounts $(31,32)$. The levels during pregnancy have not been previously described.

Our data suggest that although maternal G-CSF levels do not vary throughout gestation, a small but significant change occurs in maternal GM-CSF levels. GM-CSF is detectable in increased amounts from at least $25 \mathrm{wk}$, but normal nonpregnant adult

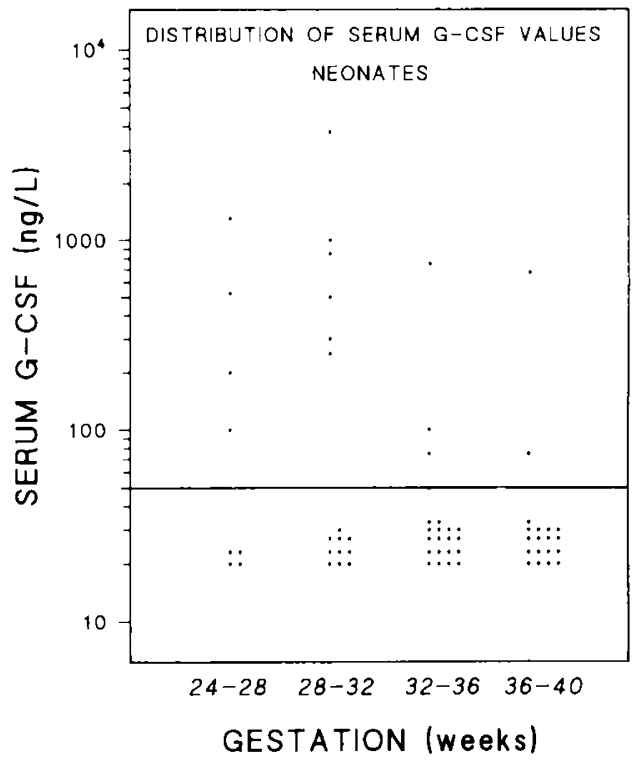

Fig. 4. Distribution of cord serum G-CSF values at delivery between 24- and 42-wk gestation.

levels are apparent at full term. The role of GM-CSF during human pregnancy remains obscure, but previous animal studies have demonstrated its production in uterine luminal or epithelial cells during early and midpregnancy $(41,42)$. The association between GM-CSF levels in 56 pairs of maternal and cord samples would be in keeping with a placental source of GM-CSF and alludes to a role in the growth and development of the fetoplacental unit. The lack of association in the corresponding G-CSF levels suggests an alternative influence, although placental production of G-CSF has also been demonstrated (43). The presence of receptors for G-CSF and GM-CSF on placental tissue $(44,45)$ would further support a role for these cytokines in normal pregnancy.

Raised serum levels of G-CSF have been demonstrated in acute infections $(33,34)$. The lack of association between infection, documented in $20 \%$ of mothers in the study, and G-CSF levels may reflect an altered response to infection during pregnancy.

In neonates, difficulty in the accurate assessment of sepsis, particularly in the premature infant (46), may have led to the underrepresentation of "infection" in this group and masked an association with a raised CSF. However, in our group of premature neonates, five $(6 \%)$ had documented early infection, a figure in keeping with the suggested rate of infection in premature infants (4). Furthermore, $31 \%$ of neonates had raised levels of G-CSF, and $32 \%$ had raised levels of GM-CSF, suggesting that infection probably does not account for all of the patients with raised CSF levels.

Neonatal G-CSF and GM-CSF levels were not associated with the presence of PIH or with the WCC or ANC, suggesting that variation in endogenous levels of G-CSF and GM-CSF with progression of gestation is independent of these variables. Our findings are in keeping with those of Cairo et al. $(37,38)$, who were unable to demonstrate G-CSF or GM-CSF in cord sera of full-term neonates using an ELISA, but our results are at variance with those of Laver et al. (36), who found high levels of both GCSF and GM-CSF in full-term cord sera using a bioassay. This discrepancy may be accounted for by the different assay techniques used. A bioassay may be influenced by other stimulatory or inhibitory factors in test sera (31), whereas ELISA is specific for a single factor $(31,47)$, although it provides no functional information. We would then suggest that raised G-CSF and GMCSF levels found in cord blood from premature neonates may have a role in fetal growth and development.

These observations are also of interest when considering the 
Table 2. Mothers: linear associations

\begin{tabular}{|c|c|c|c|c|c|c|c|c|}
\hline \multirow[b]{2}{*}{ Variable } & \multicolumn{2}{|c|}{ GM-CSF } & \multirow[b]{2}{*}{$p$ value } & \multirow{2}{*}{$\begin{array}{l}p \text { value } \\
\text { adjusted } \\
\text { for gesta- } \\
\text { tional age }\end{array}$} & \multicolumn{2}{|c|}{ G-CSF } & \multirow[b]{2}{*}{$p$ value } & \multirow{2}{*}{$\begin{array}{l}P \text { value } \\
\text { adjusted } \\
\text { for gesta- } \\
\text { tional age }\end{array}$} \\
\hline & $\begin{array}{c}>30 \mathrm{ng} / \mathrm{L} \\
(n=18)\end{array}$ & $\begin{array}{c}<30 \mathrm{ng} / \mathrm{L} \\
(n=38)\end{array}$ & & & $\begin{array}{c}>50 \mathrm{ng} / \mathrm{L} \\
(n=6)\end{array}$ & $\begin{array}{c}<50 \mathrm{ng} / \mathrm{L} \\
(n=40)\end{array}$ & & \\
\hline Gestation mean $(\mathrm{SD})^{*}$ & $232(32)$ & $250(32)$ & 0.049 & & $223(16)$ & $228(26)$ & 0.64 & \\
\hline \multicolumn{9}{|l|}{ WCC } \\
\hline Median & 13.2 & 15.4 & 0.60 & 0.33 & 18.4 & 13.0 & 0.62 & 0.68 \\
\hline Quartiles & $11.4,17.4$ & $10.9,22.4$ & & & $12.5,27.7$ & $10.6,19.0$ & & \\
\hline \multicolumn{9}{|l|}{ ANC } \\
\hline Median & 11.1 & 14.8 & 0.65 & 0.46 & 13.4 & 11.0 & 0.53 & 0.48 \\
\hline Quartiles & $8.8,25.3$ & 8.7 .49 .1 & & & $9.3,25.3$ & 7.9 .17 .9 & & \\
\hline $\mathrm{PIH}$ & $4 / 18(22 \%)$ & $10 / 38(26 \%)$ & 0.51 & 0.74 & $1 / 6(17 \%)$ & $17 / 40(43 \%)$ & 0.16 & 0.18 \\
\hline Infection & $2 / 18(11 \%)$ & $6 / 38(13 \%)$ & 0.59 & 0.87 & $1 / 6(17 \%)$ & $8 / 40(20 \%)$ & 0.60 & 0.90 \\
\hline
\end{tabular}

* Gestation period in days.

Table 3. Cord hlood: linear associations

\begin{tabular}{|c|c|c|c|c|c|c|c|c|}
\hline \multirow[b]{2}{*}{ Variable } & \multicolumn{2}{|c|}{ GM-CSF } & \multirow[b]{2}{*}{$p$ value } & \multirow{2}{*}{$\begin{array}{l}p \text { value } \\
\text { adjusted } \\
\text { for gesta- } \\
\text { tional age }\end{array}$} & \multicolumn{2}{|c|}{ G-CSF } & \multirow[b]{2}{*}{$p$ value } & \multirow{2}{*}{$\begin{array}{l}p \text { value } \\
\text { adjusted } \\
\text { for gesta- } \\
\text { tional age }\end{array}$} \\
\hline & $\begin{array}{c}>30 \mathrm{ng} / \mathrm{L} \\
(n=14)\end{array}$ & $\begin{array}{c}<30 n g / L \\
(n=44)\end{array}$ & & & $\begin{array}{c}>50 \mathrm{ng} / \mathrm{L} \\
(n=15)\end{array}$ & $\begin{array}{c}<50 \mathrm{ng} / \mathrm{L} \\
(n=50)\end{array}$ & & \\
\hline Gestation mean $(\mathrm{SD})^{*}$ & $237(24)$ & $245(35)$ & $\begin{array}{l}0.43 \\
0.019+\end{array}$ & & $221(28)$ & $239(25)$ & 0.02 & \\
\hline \multicolumn{9}{|l|}{ WCC } \\
\hline Median & 9.0 & 11.5 & 0.43 & 0.49 & 9.1 & 11.6 & 0.43 & 0.67 \\
\hline Quartiles & $7.1,18.2$ & $8.6,14.7$ & & 0.5 & 8.4 .12 .6 & $8.1,14.3$ & & \\
\hline \multicolumn{9}{|l|}{ ANC } \\
\hline Median & 3.6 & 4.4 & 0.53 & 0.29 & 3.5 & 4.1 & 0.97 & 0.20 \\
\hline Quartiles & 2.8 .6 .3 & $2.8,6.3$ & & 0.3 & 3.1 .4 .3 & $2.6,6.1$ & & \\
\hline PIH & $4 / 14(29 \%)$ & $10 / 44(23 \%)$ & 0.38 & 0.73 & $3 / 15(20 \%)$ & $18 / 50(36 \%)$ & 0.20 & 0.078 \\
\hline Infection & $1 / 14(7 \%)$ & $2 / 44(5 \%)$ & 0.55 & 0.61 & $1 / 15(7 \%)$ & $3 / 50(6 \%)$ & 0.67 & 0.95 \\
\hline $\begin{array}{l}\text { Maternal GM-CSF } \\
\text { raised }\end{array}$ & $8 / 13(62 \%)$ & $10 / 43(23 \%)$ & 0.005 & 0.007 & $3 / 14(21 \%)$ & $4 / 33(9 \%)$ & 0.37 & 0.67 \\
\hline
\end{tabular}

* Gestation period in days.

$+p$ value for quadratic association.

potential use of exogenous G-CSF or GM-CSF in the management of neonatal sepsis. Experience with the use of these factors in children and adults has indicated that G-CSF is well tolerated, is associated with few side effects, and can produce an improvement in neutrophil counts and a reduction in the number and severity of infections $(8,48-52)$. In contrast, GM-CSF has been associated with more severe side effects, particularly at higher dosage, and although neutrophil numbers were improved, the number of infective episodes was not significantly altered $(22$. 26). This difference in efficacy may relate to the respective effects of G-CSF and GM-CSF on neutrophil function. GM-CSF inhibits chemotaxis at high dosage $(12,13)$ and up-regulates neutrophil adhesion molecules (17-19), leading to sequestration of neutrophils in the circulation (53) and promotion of localized vascular damage (54). GM-CSF also promotes the release of secondary mediators such as tumor necrosis factor and IL-1 (55), which also may contribute to the production of side effects. Recently, however, Cebon et al. (56) demonstrated that the toxic effects of GM-CSF could be dissociated from its proliferative and priming effects by using s.c. rather than i.v. administration. In comparison, the effects of G-CSF are confined to the neutrophil and are not as potent in promoting neutrophil adhesion, chemotaxis, and respiratory burst activity (57).

These observations. in combination with our findings of higher levels of G-CSF and GM-CSF in the premature neonate, would suggest that G-CSF may be less toxic and more effective as an adjuvant to standard treatment of neonatal sepsis, particularly in the setting of neotropenia. GM-CSF could have a theoretical role in the management of fungal infection when the enhancement of macrophage function could be beneficial. Clinical trials of these agents are now required to establish criteria for their use and optimum therapeutic dosage.
Acknowledgment. The authors thank Dr. C. Patterson for his expert statistical advice.

\section{REFERENCES}

1. Siegel JD, McCracken GH 1981 Sepsis neonatorum. N Engl J Med 304:642647

2. Vesikari T, Janas M, Gronroos P. Tuppurainen N, Renlund M, Kero P, Koivisto M, Kunnas M. Heinonen K. Nyman R, Pettay O, Osterlund K 1985 Neonatal septicaemia. Arch Dis Child 60:542-546

3. Ferrieri P 1990 Neonatal susceptibility and immunity to major bacterial pathogens. Rev Inf Dis 4:(suppl)394-400

4. Klein JO, Marcy SM 1990 Bacterial sepsis and meningitis. In: Remington JS, Klein JO (eds) Infectious Diseases of the Fetus and Newborn Infant. WB Saunders Co. Philadelphia, pp 610-613

5. Bergqvist G, Eriksson M, Zettersom R 1979 Neonatal septicaemia and perinatal risk factors. Acta Paediatr Scand 68:337-339

6. Wilson CB 1986 Immunologic basis for the increased susceptibility of the neonate to infection. J Pediatr 108:1-12

7. Hill HR 1987 Biochemical, structural, and functional abnormalities of polymorphonuclear leukocytes in the neonate. Pediatr Res 22:375-382

8. Demetri GD, Griffin JD 1991 G-CSF and its receptor. Blood 78:2791-2808

9. Gasson J 1991 The molecular physiology of GM-CSF. Blood 77:1131-1145

10. Weisbart RH. Kwan L. Golde DW, Gasson JC 1987 Human GM-CSF primes neutrophils for enhanced oxidative metabolism in response to the major physiological chemoattractants. Blood 69:18-21

11. Kitagawa S, Yuo A, Souza LM, Saito M. Miura Y. Takaku F 1987 rhG-CSF enhances superoxide release in human granulocytes stimulated by the chemotactic peptide. Biochem Biophys Res Commun 144:1143-1146

12. Wang JM, Colella S, Allavena P, Mantovani A 1987 Chemotactic activity of rhGM-CSF. Immunology 60:439-444

13. Gasson JC. Weisbart RH, Kaufman SE. Clark SC, Hewick RM, Wong GG, Golde DW 1984 Purified hGM-CSF: direct action on neutrophils. Science 226:1339-1342

14. Wang JM, Chen ZG, Colella S, Bonilla MA, Welte K. Bordignon C, Mantovani A 1988 Chemotactic activity of rhG-CSF. Blood 72:1456-1460

15. Fleischmann J, Golde DW, Weisbart RH, Gasson JC 1986 GM-CSF enhances phagocytosis of human bacteria by human neutrophils. Blood 68:708-711 16. Roilides E, Walsh TJ, Pizzo PA, Rubin M 1991 G-CSF enhances the phagocytic 
and bactericidal activity of normal and defective human neutrophils. J Infect Dis 163:579-583

17. Cairo MS, Van deVen C, Toy C. Suen Y, Mauss D, Sender L 1991 GM-CSF primes and modulates neonatal PMN motility: upregulation of C3bi (Mol) expression with alteration in PMN adherence and aggregation. Am J Pediatr Hematol Oncol 13:249-257

18. Griffin JD, Spertini O, Ernst TJ, Belvin MP, Levine HB, Kanakura Y. Teddert TF 1990 GM-CSF and other cytokines regulate surface expression of the leukocyte adhesion molecule- 1 on human neutrophils, monocytes and their precursors. J Immunol 145:576-584

19. Buckle AM, Hogg N 1989 The effect of INF and colony stimulating factors on the expression of neutrophil cell membrane receptors. J Immunol 143:22952301

20. Frestedt JL, Gehrz R, Payne NR 1992 Modulation of immunoglobulin receptors ( $\mathrm{Fc} 3, \mathrm{Fc} 2)$ and complement receptor type 3 (CR3) on polymorphonuclear leukocytes $(\mathrm{PMN})$ from extremely premature infants (birth weight < 1250 grams). Pediatr Res 31:266a(abstr)

21. Gabrilove JL, Jakubowski A 1989 G-CSF: preclinical and clinical studies. Hematol Oncol Clin North Am 3:427-440

22. Reuf C, Coleman DL 1990 GM-CSF: pleiotropic cytokine with potential clinical usefulness. Rev Inf Dis 12:41-62

23. Andreef M, Welte K 1989 Hematopoietic colony stimulating factors. Semin Oncol 16:211-229

24. Groopman JE, Molina JM, Scadden DT 1989 Haemopoietic growth factors: biology and clinical applications. N Engl J Med 321:1449-1459

25. Platzer E 1989 Human hemopoietic growth factors. Eur J Haematol 42:1-15

26. Monroy RL, Davis TA, MacVittie TJ 1990 GM-CSF: more than a hemopoietin. Clin Immunol Immunopathol 54:333-346

27. Cairo MS, Mauss D, Kommareddy S, Norris K, van de Ven C, Modanlou H 1990 Prophylactic or simultaneous administration of rhG-CSF in the treatment of group B streptococcal sepsis in neonatal rats. Pediatr Res 27:612616

28. Yasuda $H$, Ajiki $Y$, Shimoxato T, Kasahar M, Kawada H, Iwata M, Shimizu K 1990 Therapeutic efficacy of G-CSF alone and in combination with antibiotics against Pseudomonas aeruginosa infections in mice. Infect Immun 58:2505-2509

29. Frenck RW, Sarman G. Harper TE. Beuscher ES 1990 The ability of recombinant murine GM-CSF to protect neonatal rats from septic death due to Staphylococcus aureus. J Infect Dis 162:109-114

30. Roberts RL, Szlec CM. Scates SM. Boyd MT, Soderstrom KM. Davis MW. Glaspy JA 1991 Neutropenia in an extremely premature infant treated with rhG-CSF. Am J Dis Child 145:808-812

31. Cebon J, Dempsey P, Fox R, Kannourakis G, Bonnem E, Burgess AW, Mortsyn G 1988 Pharmacokinetics of human GM-CSF using a sensitive immunoassay. Blood 72:1340-1347

32. Watari K, Asano S, Shirafuji N, Kodo H. Ozawa K. Takaku F, Kamachi S 1989 Serum G-CSF levels in healthy volunteers and patients with various disorders as estimated by enzyme immunoassay. Blood 73:117-122

33. Cebon J, Layton J, Pavlovic R, Jaria J, Dyer W, Mortsyn G 1991 Endogenous cytokine production in response to sepsis in neutropenic and non-neutropenic patients. Blood 78(suppl 1):8a(abstr)

34. Kawakami M, Tsutsumi H, Kumakawa T, Abe H, Hirai M, Kurosawa S, Mori M, Fukushima M 1990 Levels of serum G-CSF in patients with infections. Blood 76:1962-1964

35. Mizuno Y, Hara T, Nagata M. Omori F, Shimoda K, Okamura S, Niho Y, Ueda K 1990 Serum G-CSF levels in chronic neutropenia of infancy. Pediatr Hematol Oncol 17:377-381

36. Laver J, Duncan E, Abboud M. Gasparetto C, Sajhdev I, Warren D. Bussel J,
Auld P, O'Reilly J, Moore M 1990 High levels of G and GM-CSF in cord blood of normal full term neonates. J Pediatr 116:627-632

37. Cairo MS, Suen Y. Knoppel E van de Ven C. Nguyen A. Sender L 1991 Decreased stimulated GM-CSF production and GM-CSF gene expression but normal numbers of GM-CSF receptors in human term newborns com pared with adults. Pediatr Res 30:362-367

38. Cairo MS, Suen Y, Knoppel E Dana R, Park L Clark S, van de Ven C. Sender L. 1992 Decreased G-CSF and IL-3 production and gene expression from mononuclear cells of newborn infants. Pediatr Res 31:574-578

39. Placzek MM, Whitelaw A 1983 Early and late neonatal septicaemia. Arch Dis Child 58:728-731

40. Sallerfors B. Olofsson T 1991 GM and G-CSF in serum during induction treatment of acute leukaemia. Br J Hematol 78:343-351

41. Robertson SA, Seamark RF 1990 GM-CSF in the murine reproductive tract: stimulation by seminal factors. Reprod Fertil Dev 2:359-368

42. Nicola NA. Metcalf D. Johnston GR. Burgess AW 1979 Separation of functionally distinct hGM-CSFs. Blood 54:614-627

43. Hoang $\mathrm{T}$, Iscove NN, Odartchenko N 1983 Macromolecules stimulating human granulocyte colony forming cells. precursors of these cells, and primative erythoid progenitors: some apparent nonidentities. Blood 61:960966

44. Gearing DP. King JA. Gough NA. Nicola NA 1989 Expression cloning of a receptor for human GM-CSF. Eur Mol Biol Organ J 8:3667-3676

45. Uzumaki H, Okabe T, Sasaki N, Hagiwara K, Takaku F. Tobita M. Yasukawa K. Ito S. Umezawa Y 1989 Identification and characterisation of receptors for G-CSF on human placenta and trophoblastic cells. Proc Natl Acad Sci USA 86:9323-9326

46. Wientzen RL, McCracken GH 1977 Pathogenesis and management of neonatal sepsis and meningitis. Curr Probl Pediatr 8:22-35

47. Motojima H, Kobayashi T, Shimane M, Kamachi S, Fukushima M 1989 Quantitative enzyme immunoassay for human G-CSF. J Immunol Methods 118:187-192

48. Bonilla MA, Gillio AP, Ruggeiro M, Kernan NA, Brochstein JA, Abboud M, Fumagalli L. Vincent M. Gabrilove JL. Welte K, Souza LM, O'Reilly RJ 1989 Effects of rhG-CSF on neutropenia in patients with congenital agranulocytosis. N Engl J Med 320:1574-1580

49. Hammond WP. Price TH. Souza LM. Dale DC 1989 Treatment of cyclical neutropenia with G-CSF. N Engl J Med 320:1306-1311

50. Hanada T. Ono I, Hirano C. Kurosaki $Y 1990$ Successful treatment of neutropenic enterocolitis with $\mathrm{rG}-\mathrm{CSF}$ in a child with acute lymphoblastic leukaemia. Eur J Pediatr 149:811-812

51. Dale DC. Hammond WP. Gabrilove J 1990 Long term treatment of severe chronic neutropenia with rhG-CSF. Blood 76:139a(abstr)

52. Santana VM. Bowman LC, furman WWWWL, Souza LM, Crist WM 1990 Trial of chemotherapy plus rhG-CSF in children with advanced neuroblastoma. Med Pediatr Oncol 18:395(abstr)

53. Addison IE, Johnston B, Devereux S. Goldstone AH, Linch DC 1989 GMCSF may inhibit neutrophil migration in vivo. Clin Exp Immunol 76:149153

54. Vadas MA, Lopez AF. Gamble JR. Elliot MJ 1991 Role of CSFs in leucocyte responses to inflammation and infection. Curr Opin Immunol 3:97-104

55. Sisson SD. Dinarello CA 1988 Production of IL-1 and TNF by human mononuclear cells stimulated with GM-CSF. Blood 72:1 368-1374

56. Cebon J, Lieschke GJ, Bury RW, Mortsyn G 1992 The dissociation of GMCSF efficacy from toxicity according to route of administration: a pharmacodynamic study. Br J Haematol 80:144-150

57. Yuo A. Kitagawa S. Ohasaka A. Saito M. Takaku F 1990 Stimulation and priming of human neutrophils by G and GM-CSF: qualitative and quantitative differences. Biochem Biophys Res Commun 171:491-497 